\title{
Os processos de planejamento e gestão do turismo em Natal (RN) e o fomento do turismo de base local: uma articulação necessária
}

\section{The process of planning and management of tourism in Natal (RN, Brazil) and the fostering of Community-based tourism: a necessary articulation}

Christiano Henrique da Silva Maranhão, Francisco Fransualdo Azevedo

\section{RESUMO}

Motivado pela necessidade de se planejar e gerir o turismo no município de $\mathrm{Natal} / \mathrm{RN}$ de forma participativa, inserindo, igualitariamente, oportunidades que visam à participação de todos os agentes nos processos decisórios é que este artigo tem como objetivo, analisar de que forma o turismo de base local pode ajudar no redirecionamento do processo de planejamento e de gestão do turismo em Natal/RN, norteando-o para uma maior inserção da comunidade local na tomada de decisões. Do ponto de vista metodológico, este estudo se caracteriza por uma análise qualitativa, com tipologia descritivo-exploratória. As conclusões do trabalho apontam que o atual modelo de gestão do turismo vigente na capital potiguar é controlado, sobretudo pelos agentes capitalistas hegemônicos do setor e o Estado, portanto, se dá de forma contraditória, apresentando relações verticais de gestão e planejamento, em detrimento de processos horizontais. Em contraposição, o desenvolvimento endógeno, que visa à inserção da população no processo de decisão e na cadeia produtiva do turismo, apresenta-se como uma alternativa mais justa, menos excludente, mais democrática e minimizadora das contradições geradas pelo sistema capitalista no modo de planejar e gerir suas atividades, nesse caso, particularmente o turismo.

PALAVRAS-CHAVE: Planejamento; Gestão; Turismo; Comunidade Local; 


\begin{abstract}
Motivated by the need to plan and manage tourism in Natal/RN in a participatory manner by inserting equally of opportunities aimed at the participation of all stakeholders in decision making is that this article aims to analyze how tourism local basis can help in redirecting the planning and management of tourism in Natal/RN process, guiding him to a greater integration of the local community in decision making. From a methodological standpoint, this study is characterized by a qualitative analysis with descriptive and exploratory typology. The findings of the study show that the current management model of the current tourism in Natal capital is controlled mainly by the hegemonic capitalist sector agents and the state therefore occurs inconsistently, with vertical relations management and planning, rather than processes horizontal. In contrast, endogenous development, which aims at integration of the population in decision-making and tourism production chain, presents itself as a fairer, less exclusionary and more democratic alternative minimizing the contradictions of the capitalist system in order to plan and manage its activities, in this case, particularly tourism.
\end{abstract}

KEYWORS: Planning; Management; Tourism; Local Community.

\title{
Introdução
}

O turismo no município de Natal $(\mathrm{RN})$ se constitui como uma das atividades econômicas mais relevantes quanto à captação de investimentos nacionais e estrangeiros. A fase de expansão turística natalense, intitulada de Internacionalização do turismo, inicia na década de 1990, como consequência direta dos investimentos efetuados pela primeira etapa do Programa de Desenvolvimento do Turismo no Rio Grande do Norte (PRODETUR/RN), que buscava dentre as suas metas, captar de forma mais expressiva, o fluxo internacional de turistas (PROGRAMA DE AÇÃO PARA O DESENVOLVIMENTO DO TURISMO NO NORDESTE, 2002).

Desse modo, como desdobramento do programa de desenvolvimento do turismo, até o ano de 2008, verificou-se notórios investimentos de capital estrangeiro, oriundos de diversas nacionalidades. Nota-se uma inserção significativa de investimentos de agentes europeus, com destaque para: os portugueses, espanhóis e italianos.

Esta conjuntura em certa medida revela o modelo de gestão e de planejamento do turismo que é adotado em Natal/RN, o qual prioriza um escopo voltado aos interesses do capital e do público externo à localidade. Deixando evidente que a práxis do turismo natalense acaba modificando os espaços de convívio social e adotando parâmetros que seguem as exigências dos visitantes, a fim de um melhor posicionamento frente a um mercado internacional competitivo.

Deste modo, observa-se a ação das políticas públicas, valorizando as zonas litorâneas, e transformando a praia em mercadoria nobre, alterando os espaços do litoral, e convertendo-os em pontos estratégicos de recepção e distribuição de fluxo turístico, modificando com isso, a paisagem litorânea. (DANTAS, 2010).

Diante desse panorama, fica evidenciado, quer seja por meio das políticas de caráter estrutural (modificadoras de espaços), adotadas pelo 
poder público local (CRUZ, 2000), quer seja pela observação de um grande número de empreendimentos privados, casas de segunda residência e complexos turísticos de nível internacional (FONSECA, 2007), que o município de Natal, como também todas as suas interações cotidianas, vem se modificando, norteados por uma lógica externa.

Corroborando com esta informação, dados de pesquisas recentes (FRATUCCI, 2008; DANTAS, 2010) ratificam que a implantação de ações para a atividade turística acaba por provocar uma série de tensões sociais, motivadas pela maneira centralizadora de ações em função dos visitantes.

Desse modo, como resposta a uma gestão e planejamento dos espaços litorâneos em Natal/RN, que corresponde às exigências da demanda externa e do mercado internacional, intensificando as tensões socioambientais, é que se busca saber neste artigo: De que forma o turismo de base local pode se articular e colaborar para o (re) direcionamento do processo de planejamento e gestão do turismo em Natal $(R N)$, norteando-o para uma maior participação da comunidade local?

Trabalha-se o tema, a fim de analisar como o turismo de base local pode colaborar com ações de inserção do residente, na busca por um desenvolvimento local, fomentando relações mais horizontais e humanizadas. Entende-se que a comunidade local é vista como um elemento importante para o processo de planejamento e de gestão, em todos os seus níveis de ação, devido à mesma participar da dinâmica municipal cotidianamente.

Dessa forma, este artigo origina-se da percepção do turismo como uma atividade de transformação dos espaços sócio-naturais, com apelo para as relações exógenas e verticais, observando a ocorrência relacionada de uma baixa participação da comunidade local nos direcionamentos do planejamento e gestão da atividade turística natalense.

É oportuno frisar que o atual cenário teórico que compõe a temática sobre a participação da comunidade local dentro das metas e ações do planejamento e da gestão do turismo, recebe atenção de pesquisadores (COLODZEISKI, 2007; SHARPLEY; TELFER, 2008), os quais oferecem orientações sobre o tema que relaciona a correta expansão do turismo, como resultado da inserção dos moradores locais na tomada de decisão, no planejamento e na gestão da atividade.

Direcionado pelas novas tendências dos estudos turísticos, como: "descentralização da gestão; a adoção [...] de estratégias de cooperação, alianças e parcerias [...], maior comprometimento com as comunidades locais" (RODRIGUES, 2006, p.299) é que se justifica a escolha da temática deste artigo. No entanto, não se tem interesse de esgotar a discussão, mas busca-se suscitar o debate, podendo este estudo adicionar outros questionamentos ao conhecimento, já em construção.

Informa-se também que este artigo ainda expõe parte dos resultados da Dissertação de Mestrado em Turismo, defendida junto ao Programa de Pós-graduação em Turismo (PPGTUR), da Universidade Federal do Rio Grande do Norte (UFRN), intitulada de Turismo, Capital Social e Produção 
do Espaço: Uma leitura a partir do município de Natal $(R N)$ no período de 1980 a 2012.

Em consenso com autores de estudos metodológicos, a saber: Dencker (1998), Richardson (2008) e Veal (2011), este texto se caracteriza como descritivo-exploratório quanto aos seus objetivos, por buscar relacionar a temática da expansão de um turismo de base local com 0 processo de planejamento e gestão da atividade.

Tendo em vista ser o turismo um campo de estudo novo, grande parte de suas pesquisas descritivas, pode ser considerada também como exploratória. Diante disso, conforme Veal (2011), esta pesquisa se assinala como exploratória, por buscar descobrir ou descrever comportamentos em áreas ou atividades especificas. Ainda no que concerne o seu caráter exploratório, verifica-se a utilização do artifício técnico da pesquisa bibliográfica. (DENCKER, 1998).

Já no que se refere ao tratamento do objeto, nomeia-se esta pesquisa como qualitativa, por observar o homem e seus interesses como elemento norteador para o pragmatismo da análise. Para Richardson (2008, p.79) "a abordagem qualitativa, [...] justifica-se por ser uma forma adequada para entender a natureza de um fenômeno social".

Portanto, este artigo revela um caráter desenvolvido a partir de abordagens teórico-conceituais, por meio de livros e artigos científicos, que versam sobre temas de turismo de base local, participação do residente, produção do espaço e constituição de capital social. Dessa forma os dados foram ordenados para possibilitar uma interpretação coerente.

\section{O processo de planejamento e gestão do turismo no município de Natal (RN)}

Considera-se o processo de planejamento e gestão como sendo propulsor a expansão do turismo, logo, é uma das fases mais importantes no tocante ao fomento turístico de uma localidade. É neste momento que se traçam metas estratégicas, e se busca prever possíveis correções e/ou desvios de resultados, a fim de aperfeiçoar as conquistas e gerar novas possibilidades. Entende-se que o processo de planejamento e gestão do turismo, insere-se cada vez mais em uma relação movida por ações complexas, relacionando um ambiente heterogêneo e dinâmico. (ANJOS et al., 2005).

Somado a isto, o modo como esse planejamento e gestão será efetivado na localidade, sofre influências diretas de um ambiente globalizado que se orienta por meio de diretrizes neoliberais, enfatizando a livre participação do mercado, com pouca interferência do Estado. No entanto, mesmo mediado por esse ambiente que reduz sua participação, o Estado deve responder a alguns quesitos no que se refere à viabilização de obras infraestruturais, que funcionam como fator de atração de novos investimentos, dinamizando a economia local. (FONSECA; TAVEIRA, 2009). 
Para Hall (2001), o processo de planejamento compreende um conjunto de decisões a serem colocadas em prática em um futuro estrategicamente, pensado. A autora ratifica a relação necessária entre o planejamento (processo) e a política (posicionamento da administração pública frente a um aspecto da vida social). Observa-os como recursos sinérgicos, e por isso uma visão fragmentada dessas frentes de ação, pode ocasionar inúmeros descompassos para comunidade local, devido a uma gestão e planejamento desconectados.

Contraditoriamente ao que já foi exposto, nota-se que a base usada para planejar o turismo, ainda norteia-se em tendências clássicas, utilizadas no processo de planejamento urbano e regional, o que conduz os planos de desenvolvimento dos destinos, para longe de uma relação sinérgica com o planejamento de um turismo mais abrangente. Pensando do mesmo modo, os pressupostos usados pela gestão do turismo, normalmente se ligam a modelos mecanicistas, derivando-se de enfoques industriais. (ANJOS et al., 2005).

Corroborando com a fala do autor, pesquisas revelam que no município de Natal as principais intervenções em termos de gestão e de planejamento, com foco na atividade do turismo, são originadas de políticas nacionais: Os Megaprojetos Turísticos e o Programa de Desenvolvimento do Turismo (PRODETUR), ambos adotadas no RN, com desdobramentos importantes na capital potiguar, inserindo elementos aos processos de planejamento e gestão. (MARANHÃO, 2009).

Este panorama reflete o direcionamento que é dado aos processos locais, que obedecem às mudanças das relações comerciais, financeiras e dos investimentos neoliberais, sobretudo na atividade do turismo. Por essa razão, as intervenções estatais desempenham papel determinante na organização do espaço natalense, mediadas pela globalização, abertura dos mercados e internacionalização do capital e do turismo.

Ressalva-se que os fatos citados, referem-se ao estado de forma geral, mas essa realidade aplica-se em Natal, por acreditar que a lógica expressa no Rio Grande do Norte, segue paramentos já desenvolvidos na capital potiguar, uma vez que Natal é porta de entrada de investimentos turísticos estatais. Somado a isso, a capital potiguar ocupa posição privilegiada, por reunir os principais equipamentos e serviços do turismo, infraestrutura diferenciada em nível de estado, e também devido à promoção turística que é feita pelo poder público, especialmente através de divulgação do potencial turístico da capital.

Por meio de uma leitura cuidadosa, é possível verificar que as políticas de fomento ao turismo são, em sua maioria, direcionadas aos visitantes em detrimento da comunidade local. Têm-se como base dessa afirmação, os projetos aprovados e executados com recursos provindos do PRODETUR/RN, os quais são direcionados para ampliar e modernizar aeroportos, urbanização de pequenas áreas de apelo turístico, criação e melhorarias de rodovias estaduais e federais, facilitando os deslocamentos dos fluxos turísticos entre outras. É notório que as principais obras de infraestrutura, atendem diretamente ás necessidades dos visitantes e não, 
prioritariamente, da comunidade local. (PROGRAMA DE AÇÃO PARA O DESENVOLVIMENTO DO TURISMO NO NORDESTE, 2002).

Utilizando parte dos resultados da Dissertação de Mestrado, que relacionou o turismo, com a constituição do capital social e a produção espacial no município de Natal (RN), é possível identificar outros fatores que revelam a dificuldade de participação e inserção da comunidade local nos direcionamentos do planejamento e gestão do turismo no referido município.

Expõem-se a seguir, alguns enclaves que norteiam o processo de planejamento e de gestão do turismo em Natal para um caminho não participativo. Entende-se que todos esses fatores se aglutinam e derivam de um ineficaz processo de planejamento e gestão, que não insere a comunidade local nos processos que decidem os rumos do turismo. Ainda nota-se a forte pressão dos agentes hegemônicos, (Estado e agentes do mercado). Dessa forma, os fatores são:

\section{a) Inexistência de um canal de participação da população local}

No que tange 0 processo participativo da população nos direcionamentos do planejamento e da gestão em Natal, vinculado diretamente ao turismo ou favorecido por ele, o estudo evidencia que as medidas continuam sendo encaminhadas num contexto de total ausência da comunidade local, ferindo com isso o marco regulatório municipal (Plano Diretor) que assegura a participação da comunidade nas fases de formulação, na práxis e no acompanhamento desses processos sociais e coletivos.

A pesquisa do Observatório das Metrópoles - Núcleo Natal (2009) revela que este fator favorece uma conjuntura que exclui a população local da tomada de decisão, revelando erros na forma de definir o mecanismo por onde a comunidade local possa se expressar, a fim de não efetivar suas opiniões e principalmente, considerá-las. Desse modo, "percebe-se que a não participação, somada ao fato da inexistência de uma identidade do cidadão, transforma a participação da sociedade, citadas de forma unânime por toda a legislação municipal, em letra morta" (OBSERVATÓRIO DAS METRÓPOLES, 2009. p.72).

O observatório das metrópoles- Núcleo Natal (2009) ainda expõe que a mudança das metas e dos planos, com base em critérios predominantemente políticos e econômicos põe em risco outros elementos importantes, como aspectos sociais e ambientais, importantes para o interesse coletivo. Ainda comprova-se que os agentes hegemônicos (Mercado e Estado) continuam ditando as regras desse processo vertical.

Dessa forma, percebe-se que a comunidade local de Natal participa inexpressivamente dos processos que decidem onde e como a instalação e/ou expansão do turismo poderá ocorrer. Com relação à sociedade civil organizada (movimentos sociais, ONGs), tal participação também é inexpressiva. Logo os processos e controles horizontais sobre a ação do Estado são muito frágeis. Abrindo espaço para que instituições do próprio Estado, que têm crédito perante a sociedade, terminem por fazer quase que sozinho às vezes desse controle social. 
Outro fato que ratifica a inexistência da participação da comunidade local no município de Natal, é que conforme a pesquisa do Observatório das Metrópoles (2009), não foi localizada nenhum acompanhamento por parte da população ou de movimentos sociais sobre o controle da quantidade, qualidade e investimentos privados que utiliza o território como fonte de acumulação do capital por meio do turismo. A junção desses elementos (físicos, sociais, ambientais e de gestão) coloca como preocupante a forma de instalação latente dos empreendimentos imobiliário-turísticos no município de Natal.

\section{b) Capital social fragilizado}

Concatenado com a inexistência de processos participativos, nota-se a fragilidade de mobilizações, as quais podem ajudar a explicar o capital social $^{1}$ no município, com base no processo de planejamento e gestão do turismo natalense. Entende-se que diante da desigualdade social e econômica acentuada nesse espaço, a população local acaba buscando prioridades distintas e individuais. Tornando-se, pois, um desafio convencer a comunidade local sobre a ideia de que ela é responsável direta pelo destino do município. Infelizmente, devido à forte segregação, a grande maioria da população não tem interesse por questões políticas e só visam o que for vantajoso para si, individualmente, em detrimento do interesse e do bem-estar coletivo.

Contrariando esta ideia individualista, Azevedo (2008, p.100) declara que "onde as comunidades cívicas participam ativamente da política, [...], incorporando sensos de responsabilidades sociais e se imbuindo do espírito público, os avanços sociais são mais notórios". Logo, os processos horizontais de decisão pública e os interesses coletivos são mais valorizados, desencadeando notórios benefícios em prol da sociedade em sua totalidade.

Ao contrário do indicado, percebe-se que o controle social com base em processos horizontais de gestão e planejamento é cada vez mais enfraquecido, devido à existência de uma forte pressão econômica exercida sobre a pressão política, somada com a falta de princípios de ética e de confiança, os quais levam o capital social a sucumbir diante do poderio hegemônico do mercado e do Estado.

O histórico dos planejamentos e dos discursos que não se efetivam em ações práticas, é a justificativa mais utilizada segundo os resultados da Dissertação de Maranhão (2012), para explicar desmobilização e a falta de engajamento comunitário nas causas sociais, justamente por transparecer que o tempo passa, os problemas se intensificam e a participação popular não tem praticamente validade alguma diante da tomada de decisão.

\section{c) Segregação Social}

Motivado pela inexistência de participação nas agendas que decidem os rumos do turismo natalense, e pelo estímulo fornecido pelo Estado à 
especulação imobiliária, é possível visualizar uma verticalização desordenada no município.

De um lado, nota-se o surgimento de muitas construções verticais, direcionadas em grande parte, para visitantes que querem fixar moradia ou adquirir segunda residência na cidade, contraditoriamente, observa-se que boa parte da população carente de Natal encontra nas formas "ilegais", a única alternativa para solucionar o problema de moradia, negligenciado pelo Estado.

Entende-se que as áreas próximas aos espaços apropriados pela atividade turística, elevam os tributos, promovendo segregação e ocasionando um processo de migração, que afeta a comunidade local de forma acentuada. $\mathrm{Na}$ Tabela 1, visualiza-se a realidade em números, no que concernem as construções verticais.

Tabela 1: a verticalização e as transformações do espaço urbano de Natal (RN).

Table 1: verticalization and the transformation of urban space in Natal (RN, Brazil).

\begin{tabular}{l|l|l|l|l|l|l|l|l|l|l|l}
\hline BAIRRO & $\mathbf{2 0 0 0}$ & $\mathbf{2 0 0 1}$ & $\mathbf{2 0 0 2}$ & $\mathbf{2 0 0 3}$ & $\mathbf{2 0 0 4}$ & $\mathbf{2 0 0 5}$ & $\mathbf{2 0 0 6}$ & $\mathbf{2 0 0 7}$ & $\mathbf{2 0 0 8}$ & $\mathbf{2 0 0 9}$ & TOTAL \\
\hline Alecrim & - & - & - & - & - & - & - & - & - & - & 0 \\
\hline Areia Preta & 1 & 1 & 7 & - & - & 1 & - & 2 & - & - & 12 \\
\hline Barro Vermelho & - & 3 & 2 & 2 & 2 & 3 & 1 & - & 4 & 4 & 21 \\
\hline Candelária & 3 & 2 & 4 & - & 3 & 3 & 4 & 3 & - & 8 & 30 \\
\hline Capim Macio & 2 & 9 & 3 & 12 & 2 & 5 & 3 & 3 & 9 & 3 & 51 \\
\hline Cidade alta & - & - & - & - & - & - & - & - & 1 & - & 1 \\
\hline Dix S. Rosado & - & - & - & - & - & - & - & - & - & - & 0 \\
\hline Lagoa Nova & 3 & 6 & 2 & 11 & 1 & 4 & 14 & 1 & 4 & 10 & 56 \\
\hline Lagoa Seca & - & - & - & - & - & - & - & 1 & - & - & 1 \\
\hline Neópolis & - & - & - & - & - & 2 & - & 1 & 1 & 2 & 6 \\
\hline N.S. de Nazaré & - & - & 1 & - & - & - & - & 2 & - & - & 3 \\
\hline N. Descoberta & - & - & - & - & - & - & - & 1 & - & - & 1 \\
\hline Petrópolis & 2 & - & 3 & - & 2 & - & 5 & 1 & 2 & 1 & 16 \\
\hline Pitimbú & - & - & - & - & - & - & 2 & - & - & - & 2 \\
\hline Ponta Negra & 7 & 1 & 4 & 7 & 8 & 13 & 12 & 5 & 5 & 8 & 70 \\
\hline Praia do Meio & - & - & - & - & - & - & - & - & - & - & 0 \\
\hline Ribeira & - & - & - & 1 & 1 & 1 & - & 1 & - & - & 4 \\
\hline Rocas & - & - & - & - & - & - & - & - & - & 1 & 1 \\
\hline Tirol & 3 & 3 & 8 & 2 & 9 & 4 & 7 & 13 & 14 & 10 & 73 \\
\hline N.S. de Nazaré & - & - & - & - & - & - & - & - & - & - & 0 \\
\hline TOTAL & 21 & 25 & 34 & 35 & 28 & 36 & 48 & 34 & 40 & 47 & 348 \\
\hline
\end{tabular}

Fonte: Costa (2009, s/p). Source: Costa (2009, not paginated).

Nota-se diante dos dados que o processo de verticalização no município de Natal ocorre com uma rapidez preocupante, principalmente por considerar que a maioria dos empreendimentos verticais concentra-se em área de interesse turístico, a exemplo do bairro de Ponta Negra.

Conforme o Programa Integrado de Desenvolvimento Urbano e Inclusão social de Natal (2005) nota-se um grande número de loteamentos "ilegais" (35) na periferia do bairro turístico de Ponta Negra, revelando a "expulsão branca" da população local que migra para áreas com déficits de infraestrutura, motivadas pela forte pressão capitalista imposta com a chegada dos investimentos em turismo. 
É oportuno relatar diante dessa conjuntura que o turismo em Natal/RN não é includente, fato que incentiva uma expressiva segregação socioespacial, valorizando a ação dos agentes hegemônicos (Estado e Mercado) e deixando para a população local, pífias oportunidades.

Estes são os pilares dos desmandos que acometem o turismo em Natal, onde o turista é explorado (e não volta) ou é beneficiado demasiadamente com base na lógica do lucro capitalista, se apropriando do espaço e dos seus variados recursos

É importante relatar que os espaços urbanos de convívio social em Natal são constantemente modificados pela ação do homem, determinados pelo modelo capitalista de produção, trazendo sérios problemas e comprometendo o fomento de meios que asseguram uma divisão social justa. O que nota-se com freqüência é que após o espaço ser modificado para fins turísticos, ele acaba promovendo, concomitantemente, uma barreira real e outra imaginária, que impede 0 uso cotidiano e o reconhecimento do espaço pelo morador local. (MARANHÃO, 2012).

\section{d) Aumento de problemas sociais}

Como resposta a todos esses fatores já citados, os problemas sociais passam a existir de forma mais latente, motivados pelas incoerências expressas na forma de planejar e administrar a cidade e o turismo natalense. Entende-se, que como resposta a um planejamento autoritário, conservador e não participativo, surgem consequências sérias no que tange a utilização da infraestrutura, e a população residente, que utiliza desses serviços cotidianamente, é a primeira prejudicada em quesitos como: abastecimento de água, esgotamento sanitário, energia elétrica, trânsito, segurança pública, poluição sonora, poluição do ar e a poluição da praia. (COSTA, 2000).

Conforme pesquisa do Observatório das Metrópoles (2009) as dificuldades da gestão pública em Natal justificam-se diretamente pela substituição da capacidade planejadora, pela escolha de intervenções pontuais, como obras emergenciais, que acabam gerando uma política parcial e paliativa, sem criar subsídios para a composição de uma prática consistente de planejamento na área específica.

Fica evidente que devido à forte desigualdade social e econômica existente em Natal, o sentimento de desconfiança passa a existir meio às diversas relações sociais no município, o qual ainda apresenta uma reduzida parcela da população desfrutando de privilégios.

De modo geral, o cidadão não confia no poder público, portanto no Estado, tendo em vista que o mesmo se subordina ao Mercado, fomentando assim um processo ineficaz e limitado na concepção do que é "público". Logo o Estado deixa de dar o respaldo legal à população que o instituiu. Essa situação acaba incentivando as individualidades (OBSERVATÓRIO DAS METRÓPOLES, 2009).

Percebe-se que a maior parte das ações de planejamento e gestão que se vinculam ao turismo, busca a disponibilização de um território para 
receber o investidor privado, nacional e internacional, tentando justificar o fato, pelo o aumento do emprego e renda, benesse focal quando se trata da atividade turística, mas que em Natal normalmente se constitui com base numa baixa remuneração da mão de obra e precárias condições de trabalho.

Dessa forma, não é possível detectar em Natal/RN um turismo de base local, justamente por não haver incentivo por parte dos gestores, e por não haver interesse na participação social nas principais decisões do processo de planejamento urbano e turístico, bem como nos principais projetos de fomento ao turismo, e também por não haver uma valorização do turismo cultural e como consequência disso, fica impossível o turismo comunitário se configurar e espacializar.

Segundo a pesquisa de Maranhão (2012) fica latente que o nível de organização da comunidade local do município de Natal e a sua capacidade de participação no planejamento e na gestão pública são incipientes e falhos. Observa-se uma forte centralização de poder, que nega um possível modelo de desenvolvimento integrado, o qual concilie a participação política da sociedade, com a ética, a transparência e compromisso social, entre outros princípios e valores.

\section{A importância do fomento ao turismo de base local em Natal (RN)}

Diante da atual mundialização dos mercados, onde desenvolvimento local soa contraditório (CRUZ, 2008), o grande desafio para o turismo é mostrar a todos os seus gestores que, mesmo com um aumento das cifras movimentadas nas localidades, se inexistirem coesão e cooperação entre os agentes envolvidos, nos processos de planejamento e gestão da atividade, não se consegue alcançar desenvolvimento turístico algum.

A fim de contestar os danos que o mau planejamento do turismo provoca, observa-se que algumas localidades, por meio da mobilização e organização da comunidade local, desenvolvem iniciativas diferenciadas, baseadas no próprio modo de vida da localidade. Com efeito, Rodrigues (2000) enfatiza a ideia de que para se conseguir enfrentar toda esta problemática, é preciso elaborar novas políticas sociais e econômicas, das quais se resgatarão os valores culturais e relações sociais cotidianas, estimulando um desenvolvimento que se alicerça a partir da localidade.

Este estímulo ao desenvolvimento do turismo remete a ideia da construção de um desenvolvimento local, a fim de se poder lograr um desenvolvimento caracteristicamente social antes de tudo. Esta situação é confirmada por Coriolano (2003, p.64) quando a mesma afirma que:

O desenvolvimento local é o desenvolvimento endógeno, de dentro para fora, de baixo para cima, é o desenvolvimento social, o desenvolvimento do homem, das condições humanas, são as buscas de alternativas para criar novos cenários e priorizar outros atores sociais, como os trabalhadores, as mulheres, os jovens, os vizinhos, os residentes, os excluídos, os nativos, as comunidades. 
Orientando-se pela perspectiva abordada neste artigo, cabe aqui fazer uma observação no que se refere à conceituação do termo "desenvolvimento". Considera-se desenvolvimento, a aproximação dos conceitos dos autores Souza (1999) e Sen (2000), que firmam suas bases em escopos sociais para aludir o que melhor definiria o termo.

Segundo Souza (1999, p.18) desenvolvimento é "um processo de superação de problemas sociais, cujo âmbito uma sociedade se torna, para seus membros, mais justa e legítima." Seguindo essa linha de raciocínio, Sen (2000) afirma que desenvolvimento consiste na supressão de privações de liberdade que confinam as preferências e as oportunidades das pessoas de desempenhar ponderadamente sua qualidade de cidadão livremente.

Nesse sentido, entendemos que o desenvolvimento pressupõe também empoderamento da população local, isto é, dotar as pessoas, os cidadãos, o homem "simples", das condições necessárias para uma vida digna e em liberdade, na ampla acepção do termo.

Entretanto, é importante atentar para experiências em determinadas localidades, onde a população começa a apostar na forma de planejamento e gestão turística que visa um desenvolvimento de base comunitária, como meio de alcançar mais qualidade de vida, minimizando assim os problemas e os impactos negativos dessa prática social sobre o lugar.

Esta ocorrência que busca o desenvolvimento do turismo de base local, que pode ser chamado também de turismo de base comunitária (TBC), além de focar na tomada de decisão e no empoderamento por parte dos moradores locais, também tem captado atenção e se refletido em âmbito internacional, onde autores (SHARPLEY e TELFER, 2008; SEBELE, 2010) buscam inserir nas suas discussões, questões que versam sobre a participação local e sobre a responsabilidade comunitária no desenvolver do turismo.

Neste sentido, o turismo de base comunitária passa a ser visto como um influente aliado na busca por uma melhor participação popular, por meio da cooperação e do empoderamento das pessoas frente aos objetivos e metas traçados durante o processo de planejamento e gestão do turismo. Tanto se fala em desenvolvimento de base local, e desse modo, o termo se define como sendo:

Um processo de crescimento e transformação estrutural que, mediante a utilização de um potencial de desenvolvimento existente no território, conduz a uma melhoria do bem-estar da população local, sendo ela capaz de liderar este processo de transformação estrutural. (CARVALHO; NASCIMENTO, 2008, p.5).

Deste modo, acredita-se na ideia de que é possível sim, planejar e gerir o turismo como um fator capaz de suscitar novas oportunidades, contribuindo para o processo de desenvolvimento, propiciando inclusão, e sinergicamente, favorecendo a mudança atitudinal de todos os atores sociais envolvidos. 
Ao refletir sobre o turismo, Sharpley e Telfer (2007, p.150) afirmam que o turismo de base local (TBL) "é uma forma de desenvolvimento mais sustentável do que o tradicional turismo de massa, pois permite que as comunidades receptoras fujam das garras hegemônicas dos operadores turísticos e dos oligopólios das elites ricas a nível nacional." Assim, o TBL destaca-se pela inserção e empoderamento da comunidade no que se refere à tomada de decisão, participando coletivamente e em cooperação com os demais agentes do processo.

Destarte, o TBL prioriza a construção de um modelo alternativo de desenvolvimento turístico baseado na autogestão, na governança, no associativismo, no cooperativismo, na valorização da cultura local e, principalmente, no protagonismo das comunidades locais, visando à apropriação, por parte destas, dos benefícios advindos do desenvolvimento do setor de forma mais representativa. (SHARPLEY; TELFER, 2007).

Esta exposição conceitual revela a legítima aproximação e conectividade entre o desenvolvimento de um turismo de base local e a constituição efetiva da participação da comunidade local, na busca por gerar resultados com escopos sociais, revelando por meio disso, uma alternativa viável para o processo de expansão e aproveitamento do turismo em qualquer lugar, inclusive em Natal.

Ainda conforme Sharpley e Telfer (2008, p.124) "o turismo de base local é um tipo de turismo que integra altos níveis de desenvolvimento com a comunidade sob a égide da sustentabilidade". Desse modo, adota-se neste artigo a concepção de sustentabilidade, construída socialmente, ultrapassando as interfaces econômicas, e procurando equilibrar as dimensões: econômica, social e ambiental, na busca por um uso mais racional e cooperativo dos fatores e recursos.

Trata-se de redirecionar a ênfase dada para o crescimento contínuo da economia, e voltar-se para o compromisso com a preservação do meio ambiente, no qual apresenta o homem, como um de seus principais componentes. Enfim, é preciso construir e estimular a capacidade de pensar do cidadão, levando-o por meio do civismo diário, para práticas mais adequadas, "limpas" e conscientes, fazendo-os assim, ressignificar suas atitudes e o seu modo de vida (RODRIGUES, 2000).

Segundo Dantas (2005), o crescimento não se constitui ponto de partida para o desenvolvimento humano, e nem tampouco seu fim, mas antes de tudo representa um suporte. O crescimento, então, torna-se importante para assegurar a continuidade do desenvolver.

Desse modo, para que o TBL se efetive é necessário que haja espaço para relações horizontais entre todos os agentes que participam do processo de planejamento e gestão do turismo. Isso indica que o turismo não pode ser desenvolvido isoladamente pela comunidade, ou pelo poder público ou pelo mercado. Ao contrário, se todos os envolvidos se articulam e interagem de forma participativa e pautados na cooperação consegue-se formar uma base sólida para o desenvolvimento do turismo, cujos benefícios gerados contemplam a todos, especialmente a própria comunidade. 


\section{Conclusão}

Conclui-se que o Rio Grande do Norte tem se inserido no cenário turístico nacional, recebendo visitantes durante todo o ano. Isso muito se deve às políticas públicas desenvolvidas com a intenção de promover o turismo, e Natal, capital do estado, desempenha papel hegemônico e centralizador neste processo de planejamento e gestão do turismo potiguar. No entanto, esta análise evidencia que o modelo turístico adotado não tem propiciado a inserção da comunidade local nas decisões tomadas durante as etapas de planejamento e gestão da atividade.

Esta realidade sinaliza que o turismo natalense acaba sendo incentivado, na maioria dos casos, assumindo características restritas de um produto comercial, deixando de lado a ideia de que o turismo é uma prática social que remete as experiências integradoras, trocas culturais, vivência do ócio e usufruto do tempo livre, descanso, e até vincula-se ao processo de desenvolvimento social, não obstante as características e os interesses mercantis.

Sabe-se que diante da prioridade que normalmente é dada à dimensão mercadológica, ocorre um descompasso no que diz respeito ao usufruto do tempo livre e ao respeito à comunidade receptora, estimulando com isso uma descaracterização da cultura local, a elevação dos índices de vazamentos de renda, a transformação de ambientes naturais, a incitação à especulação imobiliária e a exclusão territorial de residentes, entre outros enclaves, promovidos pelas relações verticais.

Percebe-se que esses impactos são ainda mais deletérios nas localidades mais pobres, onde a expansão do turismo é apresentada como alternativa de melhoria das condições de vida, e que na essência, acaba se transformando em um fator de agravamento da situação social vivenciada na localidade devido à inexistência de uma gestão horizontal e participativa.

Desse modo, a maneira que o turismo é fomentado em Natal não tem contribuído para equalizar os benefícios proporcionados pela atividade e para a promoção das localidades e comunidades litorâneas, especialmente no que se refere a sua participação nos processos decisórios onde a atividade se desenvolve.

Os efeitos socioeconômicos do turismo em Natal mostram-se aquém de um processo justo, includente, integrador e benéfico à sociedade local. Isso seria diferente se o Estado implementasse políticas de turismo mais consistentes que visem à inclusão das comunidades, respeito aos princípios da sustentabilidade, mudando, portanto, o foco do desenvolvimento, dando oportunidades, sobretudo aos agentes turísticos locais, não privilegiando apenas os investimentos e interesses turísticos internacionais.

Dessa forma, pela inexistência efetiva de um turismo de base local em Natal/RN, é que se sugerem por meio deste artigo, possibilidades de articulação para o turismo se desenvolver a partir dos anseios e expectativas da comunidade natalense, visando à construção de ações pensadas e efetivadas a partir de relações horizontais.

Nota-se e que é possível alinhar o aumento da competitividade com melhorias das condições de vida da população. Assim, torna-se imperativo a 
construção de um novo padrão de planejamento e gestão do turismo, no qual todas as regiões possam participar desse processo de forma integrada. Isso pressupõe distanciar-se do fomento do turismo que limita a população em espaços de participação simulados, servindo apenas para convalidar e referendar decisões, anteriormente, já tomadas.

\section{Referências bibliográficas}

ANJOS.F.A. et al. Processo de Planejamento e Gestão de Territórios Turísticos: princípios norteadores de uma proposta. Turismo - Visão e Ação - vol. 7 - n.2 p. 377 - 386 maio / ago. 2005.

AZEVEDO, F.F. Desenvolvimento Local e Capital Social: uma abordagem teórica. Aracaju: Revista Geonordeste, Ano XIX, nำ1, p.87-105, 2008.

CARVALHO, J. C; NASCIMENTO, A. C. N. O turismo comunitário como fator de desenvolvimento local: o caso da comunidade barro vermelho Parnaíba/PI. Anais do II Seminário Internacional de Turismo Sustentável, Ceara, Fortaleza, p.5, 2008.

COSTA, A.A. A verticalização e as transformações do espaço urbano de Natal-RN. Tese de Doutorado. Programa de Pós-Graduação em Geografia da Universidade Federal do Rio de Janeiro. Rio de janeiro 2000.

COSTA, A.A. Número de empreendimentos verticais de Natal. 2009. Não paginado.

COLODZEISKI, A.T.D.S. Turismo e Capital Social: a experiência de desenvolvimento local sustentável no distrito de Morro Azul, Litoral Norte do RS. Dissertação de Mestrado. Universidade Federal do Rio Grande do Sul, Porto Alegre, 2007.

CORIOLANO, L.N.M.T Turismo e Desenvolvimento Social Sustentável. Fortaleza: Eduece, 2003.

CRUZ, R.C. Políticas do turismo e território. São Paulo. Contexto, 2000.

CRUZ, R.C. Turismo, produção do espaço e desenvolvimento desigual. In. BARTHOLO, R. et al. Turismo de base comunitária: diversidades de olhares e experiências brasileiras. Letra e imagem: Rio de janeiro. 2008.

DANTAS, E.W; FERREIRA, A.L; CLEMENTINO, M.L.M. Turismo imobiliário nas metrópoles. Rio de janeiro: Letra Capital, 2010.

DANTAS, A.V.S. Uma análise sobre a relação turismo e pobreza no Rio Grande do Norte. 2005. 162f. Monografia (Curso de Turismo)Departamento de Ciências Econômicas. Universidade Federal do Rio Grande do Norte, 2005.

DENCKER, A.F.M. Métodos e técnicas de pesquisa em turismo. São Paulo: Futura, 1998.

FRATUCCI, A.C. A Dimensão Espacial nas Políticas Públicas Brasileiras de Turismo: as possibilidades das redes regionais de turismo. 2008. 310f. Tese de Doutorado em Geografia- Instituto de Geociências - Departamento de Geografia. Universidade Federal Fluminense, 2008.

FONSECA, M.A.P. Tendências atuais do turismo potiguar: internacionalização e a interiorização. Maio 2007. Departamento de Geografia. Universidade Federal do Rio Grande do Norte, 2007. 
FONSECA, M.A. P; TAVEIRA, M.S. O modelo turístico potiguar e seus efeitos sócio espaciais nas comunidades litorâneas. Anais do VI Seminário da Associação Brasileira de Pesquisa e Pós-Graduação em Turismo. Universidade Anhembi Morumbi - UAM/ São Paulo/SP, 2009.

HALL, C.M. Planejamento turístico: políticas, processos e relacionamentos. Tradução de Edite Sciulli - São Paulo: Contexto, 2001.

KYTZIA, S; WALZ, A; WEGMANN, M. How can tourism use land more efficiently? A model - based approach to land-use efficiency for tourist destinations. Science Direct: Tourism Management. p 629-640.2011.

MARANHÃO, C.H.S. Análise das políticas de turismo no Rio Grande do Norte à luz da abordagem de turismo pró-pobre. 2009. 232f. Monografia (Curso de Turismo) Departamento de Ciências Administrativas - Centro de Ciências Sociais Aplicadas. Universidade Federal do Rio Grande do Norte, 2009.

MARANHÃO, C.H.S. Turismo, Capital Social e Produção do Espaço: uma leitura a partir do município de Natal de 1980 a 2012. Dissertação de Mestrado em Turismo, Universidade Federal do Rio Grande do Norte, 2012.

OBSERVATÓRIO DAS METRÓPOLES. Território, coesão social e governança democrática: Rio de Janeiro, São Paulo, Belo Horizonte, Curitiba, Porto Alegre, Salvador, Recife, Belém, Natal, Goiânia, Maringá. Relatório de pesquisa. Arranjos Institucionais para a Gestão Metropolitana Outubro, 2009.2 Disponível em: $<$ http://www.observatoriodasmetropoles.net/>. Acesso em 12 dez 2011.

OBSERVATÓRIO DAS METRÓPOLES. Relatório final de pesquisa. Linha II Dimensão sócio-espacial da exclusão/integração nas metrópoles: estudos comparativos. Estudo comparativo sobre o papel das atividades imobiliárioturísticas na transformação do espaço social das metrópoles nordestinas: Salvador, Recife, Natal e Fortaleza. 2009. Disponível em: $<$ http://cchla.ufrn.br/rmnatal/relatorio/finalimobiliarioturisticomai09.pdf $>$.

Acesso em 02 jan.2012.

PROGRAMA DE AÇÃO PARA O DESENVOLVIMENTO DO TURISMO NO NORDESTE (PRODETUR/NE). Relatório de avaliação dos impactos ambientais e sociais. 1 jan. 2002. Disponível em: <http://www.bnb.gov.br>. Acesso em: 05 abril. 2012.

PUTNAM, R.D. Comunidade e Democracia: a experiencia da Itália moderna. 5 ed. Rio de Janeiro: Editora FGV, 2006.

RICHARDSON, R.J et.al. Pesquisa Social: métodos e técnicas. 7. ed. São Paulo: Atlas, 2008.

RODRIGUES, A.B. Turismo e territorialidades plurais- lógicas excludentes ou solidariedade organizacional. In: LEMOS,A.I.G. et al. América Latina: Cidade, campo e turismo. 1 ed. São Paulo: Universidade de São Paulo, 2006.

RODRIGUES, A.M. Desenvolvimento sustentável e a atividade turística. In: SERRANO, C; BRUHNS, H.T; LUCHIARI, M.T. (orgs). Olhares contemporâneos sobre o turismo. Campinas, São Paulo: Papirus, 2000.

SEBELE, L. S. Community-based tourism ventures, benefits and challenges: Khama Rhino Sanctuary Trust, Central District, Botswana (Case Study). Science Direct: Tourism Management, p 136-146. 2010. 
SEN, A.K. Desenvolvimento como liberdade. Tradução de Laura Teixeira Motta. 4. Reimp. São Paulo: Companhia das Letras, 2000. 409 p. Título original: Development as freedom.

SHARPLEY, R; TELFER, D.J. Tourism and development: concepts and issues.Clevedon: Channel view publications, 2007.

SHARPLEY, R; TELFER, D.J. Tourism and development in the developing word. New York: Routledge, 2008.

SILVA, K.M. O processo de urbanização turística em Natal: A perspectiva do residente. 2007.128f. Dissertação de Mestrado em Geografia-Centro de Ciências Humanas, Letras e Artes. Universidade Federal do Rio Grande do Norte, 2007.

SOUZA, M.J.L. Como pode o turismo contribuir para o desenvolvimento local? In: RODRIGUES, A.B. Turismo e desenvolvimento local. 2 ed.São Paulo: Hucitec, 1999.

VEAL, A. Metodologia de pesquisa em lazer e turismo. Tradução: Gleice Guerra; Mariana Aldrigui. São Paulo: Aleph, 2011. Série turismo.

\section{Nota:}

${ }^{1}$ Conforme Putnam (2006, p.177) o capital social diz respeito às "características da organização social, como confiança, normas e sistemas, que contribuem para aumentar a eficiência da sociedade, facilitando ações coordenadas". Dessa forma, o capital social pode ser entendido como parte da sociedade civil que se organiza e reivindica por benefícios coletivos, de forma espontânea e associada na busca por ações que priorizem o bemcomum.

Christiano Henrique da Silva Maranhão: Universidade Federal do Rio Grande do Norte, Natal, RN, Brasil.

E-Mail: christianomaranhao@gmail.com

Link para o currículo Lattes: http://lattes.cnpq.br/1578152240799398

Francisco Fransualdo Azevedo: Universidade Federal do Rio Grande do Norte, Natal, RN, Brasil.

E-Mail: ffazevedo@gmail.com

Link para o currículo Lattes: http://lattes.cnpq.br/2719998085102847

Data de submissão: 30 de maio de 2012

Data de recebimento de correções: 16 de fevereiro de 2014

Data do aceite: 18 de fevereiro de 2014

Avaliado anonimamente 